\title{
AISLAMIENTO DE UN MICROORGANISMO DEL GRUPO PLEURONEUMONIAE EN ENFERMOS CON PURPURA DE SGHOENLEIN-HENOCH
}

\author{
DTes. J. MENEGHELLO, M. RODRIGUEZ, O. UNDURRAGA y R. BURDACH
}

Cótcdras de Pediatría de los Profs. A. Baeza Goni y J. Meneghello R, - Hospital Manuel Arriarán

Universidad de Chile, Instituto de Microbiología e Inimunologia. Prof. H. Vaccaro $C$.

La etiología del sindrome de SchoenleinHenoch ha sido largamente discutida por quienes se han dedicado al estudio de este cuadro; sin embargo, hasta el momento no se ha establecido exactamente cuál es el factor más importante en la patogenia de esta enfermedad. Para algunos autores sería el resultado de un proceso alérgico, pero no se ha demostrado un alérgeno específico. Alexander y Lyermann (1) señalaron como causa etiológica una hipersensibilidad alimenticia. Otros creen que sería el resultado de una lesión vascular, en cuya etiología intervendría el streptococo hemolítico (2) (3) (4)

En 1951, Carlson, Spector y Douglas (5) encontraron en la sangre de enfermos con púrpura de Schoenlein-Henoch, y en uno con absceso cerebral y meningitis, microorganismos del grupo pletroneumoniae, publicando con especial interés los casos de púrpura no trombocitopénico, por la importancia que, en un cuadro clínico de etiologia desconocida, pudiera tener este hallazgo.

En el primer caso se sospechó una fiebre por mordedura de rata, debida al streptobacillus moniliformis, ya que el enfermo presentaba una lesión ulcerada e indolora del dedo índice izquierdo, fiebre y eritema. Tres hemocultivos practicados fueron positivos para microorganismos del grupo pleuroneumoniae. El segundo caso llamó la atención, por las manifestaciones dolorosas abdominales, con sangre en las deposiciones, aun cuando las lesiones cutáneas como petequias fueron muy tenues. Dos semanas después de su primera hospitalización vuelve por exacerbación de sus molestias abdominales, siendo necesaria una intervención quirúrgica por invaginación intestinal. Loș hemocultivos practicados en ambas hospitalizaciones fueron positivos a microorganismos del grupo pleuroneumoniae. Finalmente, el tercer caso fué un cuadro clínico diferente, ya que sus manifestaciones eran de un estado infeccioso en un niño con cardiopatía congénita; en sospechas de una endocarditis bacteriana se le practicaron hemocultivos seriados que dieron resultados positivos para microorganismos del grupo pleuroneumoniae, comprobándose más tarde una meningitis purulenta y abseeso cerebral.

Las manifestaciones clínicas de dolores abdominales, con poliartritis migratoria y púrpura en los dos primeros casos, permitió descartar el diagnóstico de fiebre por mordedura de rata, debida al streptobacillus moniliformis y afirmar el diagnóstico de púrpura Schoenlein-Henoch, con el antecedente que en ambos hubo relación inmediata con una herida del tipo de una úlcera en el primero y de una mordida por humano en el segundo.

El número crecido de enfermos con púrpura de Schoenlein-Henoch, que en este úl- 
timo período nos ha tocado observar, como así mismo la gravedad que el pronóstico encierra, en un buen número de ellos (6), ha hecho imperativo el estudio más profundo de este síndrome. Por esto, el hallazgo de este microorganismo en los casos arriba resumidos, nos indujo, entre otras cosas, a efectuar una investigación dirigida con el fin de conocer si en este material clínico era posible aislar gérmenes de este grupo y qué papel en la patogenia del cuadro pudiera corresponderle.

Hasta el momento, el material a nuestra disposición lo han constituído 15 casos de púrpura de Schoenlein-Henoch hospitalizados entre 1951 y 1953 . Todos ingresaron al Servicio A de Medicina del Hospital M. Arriarán durante el primer brote de púrpura, con excepción de uno de los casos positivos a pleuroneumoniae que ingresó para estudiar su complicación renal agravada por un brote de muy corta evolución.

En esta publicación sólo nos referiremos a los 3 casos en los cuales no ha sido posible aislar este germen.

Obs. 76.0161. T. v. C. Enferma de 8 años.

Ingresa al Servicio el 17 de junio de 1951 , porque desde hacia 7 dias presentaba una erupción máculopapilar de ambas regiones gliteas y de la cara posterior de las extremiclades superiores, dolores abdo. minales de tipo cólico. que no cediant a los antiespasmódicos.

En la Sala se comprueba una enferma febril (380 C). F.n la piel habia una ertpción macular de color rojo violáceo. que no slesaparecía a la presión y cuya distribución era de preferencia en la cara de excensión cle las cuatro extremidades. A rivel del ma* léolo externo izquierdo se pudo apreciar, adentés, tina flictena de 3 cms. de diámetro de color violáceo.

Durante los primetos días de estada en la Sala su estado general se vió bastante comprometido, en es. pecial clurante las alzas febriles, va que curante las tres primeras semanas presentó febrículas de 37 y g7. 50 y esporadicamente 88 y $39^{\circ}$. En este mismo pe riodo presentó deposiciones frecuentes y teñidas con sangre, pero se normalizaron a partír dicl quinto día de evolución.

Las lesiones cutáneas que preşentaba a su ingreso palidecieron rópidamente pasa cléraparecer cturante la primera semana, pero fues de inmediato scguida por in nueve brote maculo-papular de igual lncajización al primero y cuya cvolución duró 10 días. Posteriormente no aparecieron nuevos brotes.

Al principio se sospechó compromiso renal por la palidez intensa, la facies vultuosa y una uremia de $0,70 \mathrm{grs}$. c/00; sin embargo, no hubo manifestaciones urinarias, sino a partír de fines de la segunda semana. en que apareció una albuminuria discreta, hematuria microscópica de regular intensidad $v$ escasa cilindruria. Estas manifestaciones urinarias se acentuaton intensamente hacia los 26 dias de hos. pitalización $y$ fué dada de alta con persistencia de ellas a los dos meses de estadla en la Sala. Respecto a la uremia se normalizó rápidamente después de su ingreso al servicio.

A) ser dada de alta sólo llamaban la atención las manifestaciones de compromiso renal.

De los hemocultivos, el tercero fué positivo para microorganismos rel grupo pleuroncumoniae, as! mismo fueron positivos para el mismo gennen una biopsia de piel practicada a nivel de una de las lesiones $y$ el cultivo del liquido de la flictena del malèolo externo izquierdo.

Obs. 29.519 . E. V. A. Enfcrma de 10 años.

Ingresa al Servicio el 23 de marzo de 1953, por. que destle hacía 8 días presentaba un brote cutánco caracterizado por máculas te 1 a 2 cms. de diámetro cle ubicación preferente en las rodillas, muslos y piernas, de color violáceo. Estas manifestaciones de la piel fueron acompantadas de dolores articalares fugaces y compromiso del vestado general.

A su ingreso se comprobó una enfecma en regular estado general, que acusa dolor espontáneo a nivel del epigastrio y en cuya piel se comprueban clementos de aspecto máculo-papulosos, de color rosado palido, más oscuro en el centro y localizados de prefercncia en el plano de extensión de la pierna izquierda, En ambos muslos, cono también en la reoión glútea, hipogastrio, región pectoral y superficie de extensión de ambos brazos se apreciaban máculopápulas más grandes que las anteriores, de color rojo viotáreo y algunas de base infiltrada.

Durante los prifoeros dias de hospitalización presentó clolores ahdominales de tipo cólico, que no volvierco a repetirse posterjormente.

Los clementos máculo-papulosos descritos se intensificarom apreciablemente desde el segundo día de hospitalización, especialmente aquellos urbicados en ambas piemas. Al quinto dia hizo erupción un nuevo brote cue comprometio la cara de extensión de ambos antebrazos y brazos y que regresó 4 dias des. pues.

A partir del décimo día se inició un tratamiento con cortisona. 25 mgrs, cada 6 horas dutante 3 dias, para seguir con 25 mgrs, cada- 12 horas durante 4 clias, mas aparentemente Ia evolución de las manifestaciones cutáneas no regresajon, por el contrario, aI octavo $y$ al umklécimo día de tratamiento presentó dos nuevos brotes de exantema en la cara de cxtensión de antebrazos, brazos y piernas, y algunos aislados en la región glútea.

Los examenes de orina practicados revelaron sin. drome urinario fugat al segundo y undécimo dia de evolucion. Los hemoculcivos practicados para investigar pleuroneumoniae, 2 fueron positivos de un total de 9 .

Fué dada de alta a los 30 dias de crolución en buen estado general y sin manifestaciones cutúneas ni urinaxias.

Obs. 75620. C. N. S. Enfermo de 6 años de edad.

Ingresó al Servicio el 29 de diciembre de 1952 . porque dcsde hacia 9 dias presentaba dolores abdo. minales intenscs de tipo cólico y una erupción petequial de la piel sle las extremidades.

Al examen físico de ingreso se encontró un nin̄o ę deficiente estado nutritivo con un estado general muy comprometido, con rlolor intenso y espontáneco abdominal, que presentaba en la piel elementos máculo-papulosos de color rojo parduzco, preferentemente en los planos de extensión de las extremidades 
inferiores y mas escasus en la regiótl glútea y en los miembros superiores.

Intranie los primeros 6 dias de estada en la Sala. st evolución se caracterizó por dolores colicos abdominales intensos $y$ la crupción máculo-papulosa te la piel regreso lentamente en el curso tle 8 dias, a raiz de lo cual el estado general, que se hab'a mantenido muy comprometido, mejoró rúpidamente, clesaparecicndo tambicin los dolores abdominales.

Los exámenes de orima demostraron a partir del segundo día albuminuria discreta $y$ hematuria microscópica escasa. Fuci dida de alta a lós 29 dias de estada, manteniendo su sindrome urinario de poca intensidarl, lúc controlado en policlinics postcriormente, donde 2 mescs mass tarde de st alta, a raíz de un brote de exantema fugaz, se exacerbayon sus manifestaciones urinarias. En el examcn practicado en esta oportunidad se comprobó un enfermo pálido con facies algo sultuosa, con discreto edema palpabral y discreta hipestensión arterial.

Se hospitaliza para estudiar esta complicación rcnal, comprobándose durante cste tiempo una oliguria de 2tu cc. diarios y un sindrome urinario, gue pcrsistió durante los primercos 40 dias de hospitalización, desapareciendo posteriormente. Las matrifestaciones de hipertensión y exlema desaparecieron rápidamente dcspués de ingresato, normalizándose tambićn la presión arterial.

De Ios 7 hemocultivos practícados en esta eportunidad para investigar gérmenes del grupo pleuronelumonfa, uno fue positivo. La investigación de anticuerpos y el test de sensibilidad cutánea al germen aislado fueron negativas.

Fué dado de alta a los $\mathbf{5 3}$ días de estada sin signos de compromiso renal.

\section{Investigación bacteriológica}

Material y métodos. La investigación de estos microorganismos la realizamos a través de hemocultivos seriados, que fueron tomados mañana $y$ tarde, en especial durante las alzas febriles. Sólo en el primer caso nos fué posible practicar, además, el cultivo de un trozo de piel obtenido por biopsia a nivel del maléolo externo.

Los hemocultivos fueron practicados en caldo triptosa difco y observados durante 10 días, realizando resiembras desde el $4^{\circ}$ ? día a medios sólidos -agar triptosa difco- y a medios líquidos enriquecidos con $20 \%$ de plasma humano o suero de bovinos, con el fin de observar sus caracteres morfológicos, bioquímicos $\mathrm{y}$ ciclo evolutivo.

Las muestras obtenidas por biopsia de la piel y del líquido flictenular, en el primer caso, fueron sembradas en medios líquidos caldo triptosa difco y seguidos posteriormente en igual forma que los hemocultivos.

Resultados. Al $6^{\circ}$ día de incubación a $37^{\circ} \mathrm{C}$ se pudo observar en un bemocultivo del primer caso y alrededor del $4^{9}$ día en los hemocultivos de los 2 casos restantes, un enturbiamiento muy tenue, que en los días siguientes tendia a formar un fino sedimento en las paredes y fondo de los fras$\cos y$ tubos. Estos mismos caracteres iniciales de cultivo se observaron en los medios donde se habían sembrado la biopsia de piel y el líquido de la flictena.

El análisis microscópico realizado mediante el procedimiento de Dienes, nos reveló un microorganismo polimorfo, cuyos elementos los formaban bacilos de diferentes tamaños, filamentos finos y cocoides, a la vez que formas extravagantes, particularmente moniliformis (fotos $2 \mathrm{y} 3$ ). El estudio posterior de estos mismos cultivos y de las resiembras, realizado diariamente, nos de-

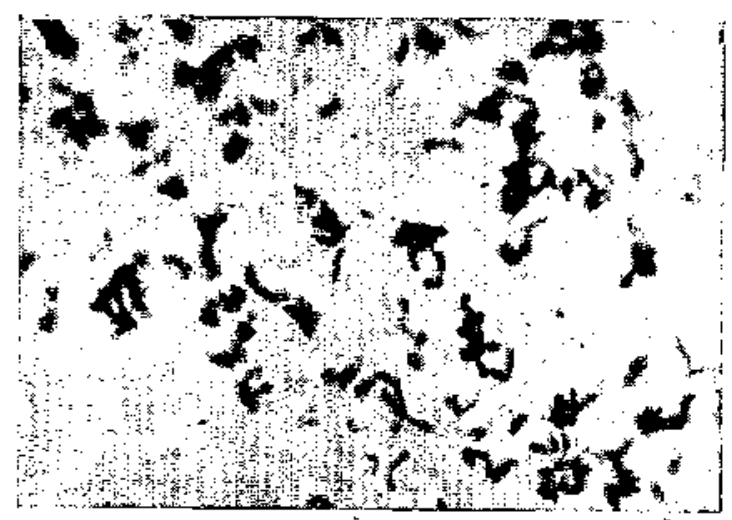

Microfotogralia 2

Cultivo de 48 horas en agar triptosa re la cepa VA. en el que se pueder apreciar, además del polimotfísmo caracteristico. las formas muniliformis $y$ bacilares.

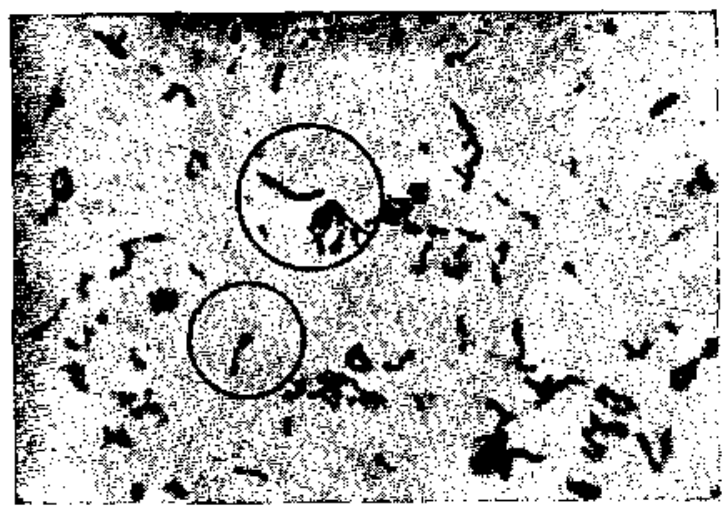

Microfotografia 3

Cultivo de 4 dias de la cepa VA en agar triptosa; en ella se pueden distinguir las formas anulares, y en los ctrculos una forma cocoicle, emitiendo un filamento, las formas esferoidales grabulares y algunas moniliformis. 
ostró la presencia de elementos caracterís:os del germen, como son los grandes cuers esféricos (fotos 4 y 5), las formas anues y las formas cocoides que emiten finentos. Estas estructuras, unidas a los ros aspectos descritos, así como a la mor-



Micrototografia 4

Itivo de 4 dias en caldo suewo de bovino de la cepa , en el que se pueden distinguit los micrococoides grínulos elcmentales y algunos grandes cuerpos esféricos.

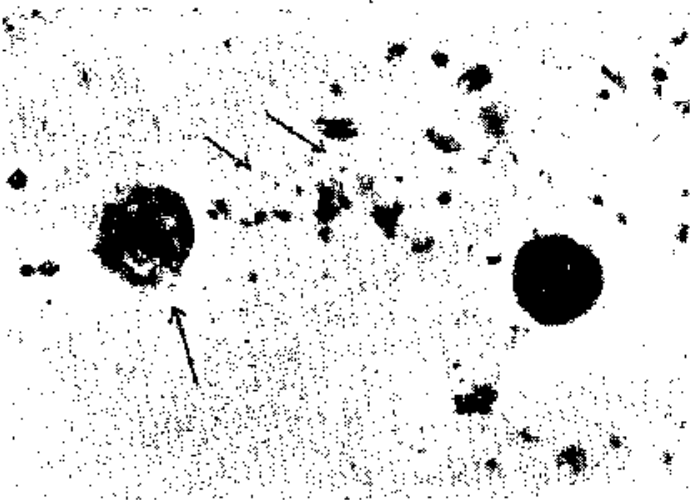

Microfotografía :

tivo de 4 dias de la cepa Vergara en caldo trip1. Representan a gran attmento los grandes cuer-

esféricos con su estructura gramular interna, cndo a Ios dos y distribuídos caprichosamente en zampo se ven finsimos filamentos de micrococoidles. aprccian, además, formas anulares y semejantes i levaduras.

cgía de las colonias, que revelaron tener tamaño descrito para las colonias de los croorganismos del grupo pleuroneumoie, a la vez que su característica forma centro solevantado y más oscuro (fotos y 1'), nos permitieron sospechar fundanente que estábamos en presencia de un sroorganismo del grupo pleuroneumoe. Sólo nos quedaba por comprobar sus caracteres bioquímicos y su aspecto experimental en animales para certificar este hallazgo. Esto lo pudimos comprobar, desde que ellos no se desarrollaron en medios corrientes de cultivos, sino que sólo en medios altamente enriquecidos con proteínas y aun en medios de agar sangre sólo fué posible hacerlos crecer en algunas de las resiembras.
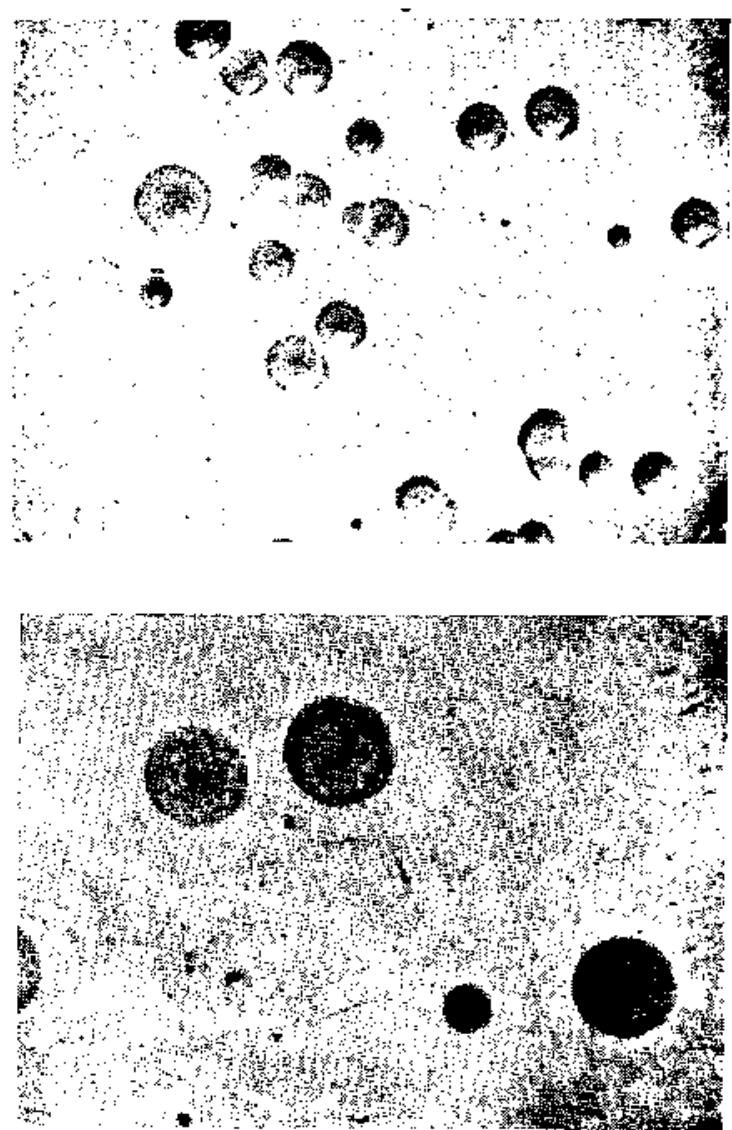

Mictofotografías I $^{\prime} \mathrm{I}^{\prime}$

Colonias de plcuroneumonfa cepa NS, fotografiadas mediante iluminación lateral

Las inoculaciones realizadas en lauchas blancas por diferentes vías fueron negativas, pero en cambio se desarrollaron bien en membrana corioalantoides de embrión de pollo.

Con las dos últimas cepas obtenidas se trató de demostrar anticuerpos en los enfermos, de los cuales habían sido abtenidas, pero esta investigación fué negativa. Del mismo modo fueron negativos los tests de sensibilidad cutánea realizados. En relación a estas dos últimas pruebas, podemos 
decir que sus resultados en el sentido de indicar una infección en actividad son de poco valor por lo irregular, ya que en sujetos de los cuales han sido aislados estos gérmenes $y$ que evidentemente presentan una infección por ellos, además que se ha podido descartar toda otra causa de un proceso infeccioso, estas pruebas no siempre han resultado positivas.

De acuerdo al criterio de Sabin (7) son dos las características fundamentales que permiten clasificar estos gérmenes dentro del grupo pleuroneumoniae:

1) Las características de las colonias al ser traspasadas de medios liquidos a sólidos que tengan igual composición bioquímica que los primeros.

2) El pleomorfismo bacteriano y sus caracteres de tinción.

Nuestras cepas han coincidido en sus características con los postulados dados por Sabin, lo cual nos ha permitido su clasificación dentro del grupo en estudio.

\section{Comentario}

Los microorganismos del grupo pleuroneumoniae constituyen un conjunto de gérmenes pleomórficos, visibles al microscopio corriente $y$ que en cuyo ciclo de evolución presentan formas filtrables. El prototipo de ellos es el agente etiológico de la pleuroneumonía de los bovinos (8), siendo preferentemente patógenos para los animales. Sin embargo, ya sea formando parte de la flora normal de ciertas porciones del organismo humano o como verdaderos agentes patógenos en otras oportunidades, han sido aislados en el hombre (5) (9) (10) (11).

Sus caracteres morfológicos y de cultivos son sin duda los elementos más interesantes, ya que presentan una serie inmensa de formas que van desde las granulares hasta las cocoides y anulares y desde el bacilo corto hasta el filamento ramificado. Junto a estos aspectos de cultivo es posible observar formas extrañas y extravagantes de difícil descripción. Sin duda, uno de elementos más importantes en su ciclo evolutivo $y$ en $s u$ aspecto microscópico es el "gran cuerpo esférico" (large round boby), que es un elemento globuloso de 10 micrones de diámetro más o menos. Posee una estructura granular y al romperse dejan en libertad estos gránulos en el ambiente, siendo ellos el punto inicial del ciclo evolutivo de la bacteria.

Muy difíciles de cultivar, no se desarrolan en los medios corrientes de cultivos, sino que requieren medios altamente enriquecidos con proteínas. En ellos es posible evidenciar su desarrollo alrededor del cuar. to día de incubación, revelándose por enturbiamiento leve de los medios líquidos o por el desarrollo, en los medios sólidos, de colonias finísimas de centro solevantado y más oscuro, que tienen un diámetro de 10600 micrones $y$ que requieren de iluminación lateral y aumento para su estudio.

Son gram negativos, pero se tiñen muy difícilmente con este procedimiento; son mejor evidenciados mediante la tinción de Giemsa o por el procedimiento de Dienes con una solución alcohólica saturada de azul de metileno (12).

Se les conoce también con el nombre de "microorganismo L", nombre dado por Klienenberger (13), quien los ha estudiado detenidamente en su aspecto morfológico y ciclo de evolución. Ha descrito una serie de tipos en bases a sus caracteristicas biológicas e inmunológicas. Estos han sido designados por L1, L2, L3, etc. Probablemente uno de los tipos más interesantes es el LI, sobre el cual mucho se ha discutido si representa una fase del streptobacillus moniliformis a si se encuentra en simbiosis con esta bacteria (14) (15) (16).

Respecto a su poder patógeno en el hombre, no es bien conocido. Han sido aislados en ciertos procesos patológicos como cervicitis, uretritis y prostatitis. A este respecto es interesante destacar que si bien estos gérmenes han sido encontrados normalmente en el tracto genital de la mujer, Dienes $y$ cols. (17) los aislaron en $\mathbf{5 8}$ hombres, los cuales tenian signos evidentes de infección uretral o prostática y de ellos 18 presentaban, además, artritis y en 9 de éstos sus manifestaciones clínicas podian perfectamente encuadrarse con los síntomas del síndrome de Reiter, y aun fué posible aislar el germen en dos de estos casos del líquido sinovial. Sin embargo, aun su acción sobre los organismos humanos no está bien definida.

El aislamiento de microorganismo de este grupo en el síndrome de Schoenlein-Henoch nos ha parecido de suficiente interés para destacarlo y llamar la atención sobre la importancia que él pudiera tener en la patogenia del cuadro. 
No podría ser considerado este hallazgo como mera coincidencia desde que el germen fué repetidamente aislado del mismo enfermo y desde que en un caso se encontró en las lesiones cutáneas y èn el líquido flictenular.

Si pensamos que estos microorganismos, especialmente el tipo $\mathrm{L} 1$, no se ha definido exactamente cuál es su posición respecto al streptobacillus moniliformis y que las manifestaciones clínicas del púrpura de Schoenlein-Henoch, particularmente las poliartritis y el exanterna, semejan las manifestaciones de la fiebre por mordedura de rata debida al streptobacillus moniliformis; que aun más, en los casos descritos por Carlson y cols. hubo evidencia de lesiones por mordeduras, en dos de ellos nos damos cuenta que existen clinicamente puntos de contactos entre la fiebre por mordedura de rata por un lado y el síndrome de SchoenleinHenoch. Sin duda que la confirmación bacteriolbgica de estos casos sería el elemento de mayor valor para determinar cuál es la importancia de estos microorganismos en el cuadro que comentamos. El hallazgo de gérmenes de este grupo en poliartritis y especialmente en el síndrome de Reiter, que se caracteriza por artritis, conjuntivitis $y$ uretritis, podría ser otro punto de apoyo en la similitud de las infecciones por estos microorganismos y aquéllas causadas por el streptobacillus moniliformis, que en su forma clásica adquiere el nombre de fiebre por mordedura de rata o enfermedad de Haverhill.

Los caracteres diferenciales dados por quienes se han dedicado al estudio de estos gérmenes para separar el tipo L1 del streptobacillus moniliformis, en especial frente a la inoculación experimental, son detalles tan finos de investigación que no dejan absolutamente convencidos de la dualidad de bacterias. En los casos por nosotros encontrados, tanto por los caracteres de cultivos y experimentales como por el cuadro clínico de los pacientes, sugieren fuertemente la posibilidad que ellos sean del tipo L1. Las microfotografias insertadas anteriormente muestran evidentemente formas moniliformis, que caracterizan, por otra parte. al streptobacillus moniliformis.

Podría pensarse que la falta de mayor comprobación bacteriológica de la existencia de estos gérmenes en procesos patológicos como el que comentamos, derivan fun- damentalmente de las dificultades técnicas para estudiarlos $y$ de la falta de familiaridad con microorganismos que requieren de técnicas especiales para evidenciarlos. De este modo es probable que muchas veces pasen desapercibidos en Jos cultivos. De aquí entonces que un estudio dirigido de estos casos podlía traernos un mejor conocimiento de la acción patógena de los microorganismos del grupo pleuroneumonía, a Ia vez que esclarecer hasta dónde existe un cuadro clínico clásico que corresponde a una infección por ellos y las demás manifestaciones no sean sino variaciones clínicas de un estado infeccioso a un mismo germen.

\section{Conclusiones}

1. Se presentan 3 casos de púrpura de Schoenlein-Henoch, en cuya evolución fué posible aislar un microorganismo del grupo pleuroneumoniae.

2. Se da a conocer el aspecto bacteriológico detallado que permite clasificar nuestras cepas dentro del grupo.

3. Se señala el interés del hallazgo y se discute el papel patógeno de esta bacteria en los cuadros clínicos presentados y en otros similares.

\section{Conclusions}

1. Three cases of Schoenlein-Henoch purpura in which an organism of the pleuropneumonia group was isolated are described.

2. A detailed bacteriological study is presented.

3. The pathogenic role of this bacterium is discussed.

\section{BIBLIOGRAFIA}

1. ALEXANDER, H. F EYERMANY, C. (citados por Lctitt, L. and Burbank, B.) -Ann. Int. Med. 35: $1378,1951$.

2. GLARZMANN, E-Lecciones de Pedintria, Ed. Labor. Barcclona, 1951. P. 406.

3. GAIDNER, D.-The Schoenlein.Henoch syndrome. (Anaphylactoid Purpura), Quart. J. Med. 17: 95, 1948 .

4. DERHAM, R, and ROGERSON, M.-The Schoen. lein-Henoch syndrome and collagen disease. Arch. of Dis. of Childhood 27: $139,1952$.

5. CARLSON, H., SPECTOR, $S$. and DOUGLAS, H.-Possible role of Pleuropneumonia like organisms in eliology of Disease in Childhood. Am. J. Dis. of Children 81: 193, 1951. 
6. BURDACH, R. Y MENEGHELLO, J,-Sindrome de Schoenlein-Henoch (Estudio clínico de 39 casos). Revista Chilena de Pediatria 23: 11-12, 1952.

7. SABIN, A. B.-The pleuropneumonia group. Bac: tetial and Mycotic Infections of Man, P. 568 . Editado por Dubos, R. J. J. B. Leppincott Co. 1948.

8. NOCARD y ROUX.-Le microbe de la Pleuropneumoniae. Ann. Inst. Pasteur 12: 240, 1898.

9. KLIENENBERGER, E. and NOBEL, E.-Pleuropneumonia-Like Organisms in Human Vagina. Lancet. 2: 46, 1945 .

I0, SALAMAN, M. H., KING, A. J., BELL, H. J.. WLKINSON, A. E., GALLAGER, E., KIRE, C.. HOWORTH, l. and KEPPICH, P. H.-The isola. tion of the Organisms of the Pleuropneumonia group from the genital tract of men and women. J. Path. Bact. 58: 31, 1946.

11. SABIN, A. B. and JOHNSON, B.-Search for microorganisins of the Pleuropneumonia group in Rheumatic and non-Rheumatic Children. Proc. Soc. Exp. Biol. and Med. 44: 565, 1940.

12. DIFNES, I.-Morphology and Nature of the Pleuropneumonia-Lipe organisms, J. Bact. 50: 441, 1945.
13. KLIENENBERGER, E.-The PleuropneumoniaLike organisms. Further stodies and a descriptive account of recently discovered type. J. Hyg. 40: 204, 1940.

14. KLIENENBERGER, E-Natutal accurrence of PJeuropneumonia-Like organisms in apparent şmbiosis with Streptobacillus Moniliformis and other bacteria. J. Path Bact. 40: 93, 1985.

15. KLIENENBERGER, E.-Some new observation bearing on the nature of the PleuropnettmoniaLike organisms known as $\mathrm{Ll}$ assnciated with Streptobacillus Moniliformis. J. Hyg. 42: 485, 1942.

16. DIENES, L.-Organisms of Klienenberger and Streptobacillus Moniliformis. J. I $7 \mathrm{f}$. Dis. 65: 24, 1939.

17. DIF.NES, L, ROPES, M. W, SMLTH, W. E, MADOIF, $S$. and BAUER, W-Medical Progress: The role of Pleuropneumonia-Like organismos in Genitourinary and Joint diseases. Ncw England J. Med. 238: $500,1948$.

18. TURNER, A. W.-A study of the morphology and life cicle of the Organisms of Pleuropneumonia contagious Bovinum (Borrelouvces Perineumonia. Nov, Gen.) by observations in the living state un. der dark ilumination. J. Path. Bact. 11: 1, 1935. 